\title{
The Gas-Phase Kinetics of Reactions of Alkali Metal Atoms with Nitric Oxide
}

\author{
A. Goumri, J.-D. R. Rocha, Ashutosh Misra, ${ }^{\dagger}$ and Paul Marshall* \\ Department of Chemistry, University of North Texas, P.O. Box 305070, Denton, Texas 76203-5070
}

Received: July 13, 1999; In Final Form: September 15, 1999

\begin{abstract}
Time-resolved atomic resonance absorption spectroscopy was employed, with flash-photolysis generation of atomic potassium and sodium at $734 \mathrm{~K}$, to investigate the kinetics of $\mathrm{K}+\mathrm{NO}+\mathrm{Ar}$ and $\mathrm{Na}+\mathrm{NO}+\mathrm{Ar}$. The low-pressure limit recombination rate constants are $(1.0 \pm 0.2) \times 10^{-31}$ and $(1.9 \pm 0.5) \times 10^{-32} \mathrm{~cm}^{6}$ molecule $\mathrm{e}^{-2}$ $\mathrm{s}^{-1}$, respectively. Mainly ionic, triplet state adducts are predicted. RRKM modeling yielded $\mathrm{K}-\mathrm{NO}$ and $\mathrm{Na}-$ NO bond dissociation enthalpies of 104 and $66 \mathrm{~kJ} \mathrm{~mol}^{-1}$, which compare well with UQCISD(T)/6-311+ $\mathrm{G}(2 \mathrm{~d})$ ab initio values of 81 and $68 \mathrm{~kJ} \mathrm{~mol}^{-1}$, respectively. For $\mathrm{Li}+\mathrm{NO}+\mathrm{Ar}$, the predicted binding energy is $134 \mathrm{~kJ} \mathrm{~mol}^{-1}$, which yields a predicted rate constant of $1.4 \times 10^{-31} \mathrm{~cm}^{6}$ molecule ${ }^{-2} \mathrm{~s}^{-1}$.
\end{abstract}

\section{Introduction}

There have been numerous studies of the addition reactions of alkali metal atoms to oxygen and sulfur dioxide, ${ }^{1-6}$ motivated in part by the importance of these reactions to the atmospheric and combustion chemistry of group 1 metals. ${ }^{7,8}$ Recently, catalytic cycles involving alkali metals have been proposed for the destruction of nitrous oxide in combustion exhaust gases, ${ }^{9}$ and to assist the removal of $\mathrm{NO}_{x}$ in the selective noncatalytic reduction process. ${ }^{10}$ While the bimolecular reaction kinetics of alkali metals with $\mathrm{N}_{2} \mathrm{O}$ are well characterized, ${ }^{6}$ reactions with other nitrogen oxides are not. The present work is the first direct study of the processes

$$
\begin{gathered}
\mathrm{K}+\mathrm{NO} \rightarrow \text { products } \\
\mathrm{Na}+\mathrm{NO} \rightarrow \text { products }
\end{gathered}
$$

in the gas phase. Time-resolved atomic resonance absorption spectroscopy was employed, together with flash-photolysis generation of sodium and potassium atoms, to measure the rate constants $k_{1}$ and $k_{2}$ for reactions 1 and 2 . Adduct formation was observed, which is consistent with the low bond strengths of the alkali $\mathrm{A}-\mathrm{O}$ and $\mathrm{A}-\mathrm{N}$ diatomic molecules $(\mathrm{A}=\mathrm{K}, \mathrm{Na}$, $\mathrm{Li}),{ }^{11-15}$ that make abstraction reactions endothermic by at least $290 \mathrm{~kJ} \mathrm{~mol}{ }^{-1} \cdot{ }^{13,15} \mathrm{Ab}$ initio analyses of the potential energy surfaces (PESs) were carried out to provide information about the nature of possible adducts between alkali metal atoms and $\mathrm{NO}$ and their thermochemistry. The results were employed in RRKM analysis of the kinetics of reactions 1 and 2, to rationalize $k_{1}$ and $k_{2}$ and to yield a prediction of the rate constant $k_{3}$ for the reaction

$$
\mathrm{Li}+\mathrm{NO} \rightarrow \text { products }
$$

\section{Experimental Procedures}

The atomic metal, sodium or potassium, was generated by pulsed UV photolysis of the metal iodide vapor, in the presence of a large excess of NO, so that the reaction occurred under pseudo-first-order conditions. Time-resolved resonance absorption spectroscopy was used to monitor the concentration of metal (M).

\footnotetext{
* Corresponding author: marshall@unt.edu.
}

To generate metal iodide vapors, temperatures of approximately $734 \mathrm{~K}$ were employed. These temperatures were reached with the use of a stainless steel reactor, as described earlier, ${ }^{4}$ with some minor modifications. Briefly, one sidearm used to hold the combustion boat containing the metal iodide was wrapped and wired separately to a variable transformer. This setup provided different temperatures for the metal iodide source and the reactor center. The temperature in the reaction zone was measured by a movable thermocouple, with an estimated accuracy of $\sigma_{\mathrm{T}} / T \approx 2 \%$. The stability of the temperature in the reaction zone was assessed by comparing the difference between the initial and final temperatures, $\delta_{\mathrm{T}}=\left|T_{\mathrm{I}}-T_{\mathrm{F}}\right|$, to the average of these temperatures, $T_{\text {avg }}=\left(T_{\mathrm{I}}+T_{\mathrm{F}}\right) / 2$; over all experiments $\delta_{\mathrm{T}} / T_{\text {avg }} \approx 4 \times 10^{-3}$.

Atomic metal was generated by flash-lamp photolysis through a Suprasil window. [Na] and [K] were monitored by absorption of resonance radiation from an AC-powered sodium spectral lamp or a DC-powered potassium hollow-cathode lamp, respectively. The $D$-lines for sodium at $589.8 \mathrm{~nm}$ and potassium at $766.5 \mathrm{~nm}$ were isolated with an Oriel 77250-monochromator operated at $0.12 \mathrm{~nm}$ resolution. The transmitted light intensity through the reaction zone, $I$, was measured with a red-sensitive Hamamatsu R-1477 photomultiplier tube. Then, the output was amplified (Thorn EMI C632-A1) before capture in a computercontrolled digital oscilloscope (Rapid Systems R402). Delay between triggering the flash lamp and the oscilloscope allowed measurement of the unattenuated signal $I_{0}$ before each photolysis pulse, as well as the variation of $I$ with time during reaction. Signals from up to 128 pulses were digitized and averaged before storage in the computer for analysis. This averaging yielded a flat $I_{0}$ from the AC sodium lamp.

Fresh gas mixtures flowed slowly through the reactor to replace reagents and remove products between photolysis pulses, with an average gas residence time $\tau_{\text {res. }}$. This achieved a kinetically quasi-static system because the reaction time scale was much shorter than the time required for gases to be swept out of the reaction zone.

Argon (Linde 99.997\%), the bath gas, was used as supplied without any further purification. Emphasis was placed on avoiding effects of impurities in the $\mathrm{NO}$ gas because $\mathrm{N}_{2} \mathrm{O}$ and $\mathrm{NO}_{2}$ are both potentially highly reactive toward atomic alkali 
metals. Gases from two commercial suppliers, Matheson Gas Products and MG Industries, and the product of our own synthesis, were employed. The following reaction was used for laboratory synthesis: ${ }^{16}$

$$
\mathrm{KNO}_{3}(\mathrm{~s})+3 \mathrm{KNO}_{2}(\mathrm{~s})+\mathrm{Cr}_{2} \mathrm{O}_{3}(\mathrm{~s}) \rightarrow 2 \mathrm{~K}_{2} \mathrm{CrO}_{4}(\mathrm{~s})+4 \mathrm{NO}
$$

A large test tube containing the solid reagents was connected to the Pyrex vacuum line and pumped down to approximately 0.01 mbar to prevent oxidation of $\mathrm{NO}$ to $\mathrm{NO}_{2}$ by atmospheric $\mathrm{O}_{2}$. Heat from a Bunsen burner initiated the reaction. Purification of the NO gas took place in two stages. The NO was passed through charcoal and $\mathrm{FeSO}_{4}$ traps to remove $\mathrm{N}_{2} \mathrm{O}_{5}$. Further purification consisted of distillation cycles at $196 \mathrm{~K}$ using an acetone $/ \mathrm{N}_{2}(\mathrm{l})$ slush bath to trap the nitrogen oxides $\mathrm{NO}_{2}, \mathrm{~N}_{2} \mathrm{O}_{4}$, and remaining $\mathrm{N}_{2} \mathrm{O}_{5}$. At $175 \mathrm{~K}$, a methanol/ $\mathrm{N}_{2}(\mathrm{l})$ slush bath was used to remove $\mathrm{N}_{2} \mathrm{O}$. Typically, about four cycles were required to obtain a pure white condensed gas. It is worth noting that both commercial $\mathrm{NO}$ gases required extensive purification.

Gas mixtures were prepared by addition of 500-1200 mbar of Ar to 5-50 mbar of NO in a 5 L Pyrex storage bulb. Pressures were measured with an MKS Instruments Type 226A capacitance manometer system. Gas flows were set using massflow controllers (MKS Instruments Types 1159A and 1159B), calibrated against a Teledyne-Hastings HBM-1A bubble meter. Flow rates ranged from 200 to $900 \mathrm{sccm}$ for Ar and $0-50 \mathrm{sccm}$ for NO/Ar mixtures. Mixing of these flows, through a stainless steel tube, occurred before entrance to the reactor. Through the other reactor sidearms, an additional small flow of Ar (typically $10 \%$ of the main Ar bath flow) was used to sweep the zone in front the PMT, flash lamp, spectral lamp, and the arm containing the metal iodide vapor to prevent a build up of reaction products, and to sweep the metal iodide vapor to the reaction zone center.

A large ratio of $[\mathrm{NO}]$ to the initial concentration of atomic metal, $[\mathrm{A}]_{0}$, provided pseudo-first-order kinetics for the loss of A, with $k_{\mathrm{ps} 1}$ as the pseudo-first-order rate constant for [A] decay.

$$
-\mathrm{d}[\mathrm{A}] / \mathrm{dt}=k_{\mathrm{ps} 2}[\mathrm{~A}][\mathrm{NO}]+k_{\mathrm{diff}}[\mathrm{A}]=k_{\mathrm{ps} 1}[\mathrm{~A}]
$$

$k_{\mathrm{ps} 2}$ is the pseudo-second-order rate constant for the reaction, and $k_{\text {diff }}$ accounts for the loss of metal by other means, primarily diffusion from the reactor center. Depending on the experimental conditions, $k_{\text {diff }}$ was in the range $60-300 \mathrm{~s}^{-1}$ for both reactions 1 and 2. Combination with the Beer-Lambert Law yields the equation for the time-resolved transmitted light intensity. ${ }^{4}$

$$
I(\mathrm{t})=I_{0} \exp \left[-\epsilon l[\mathrm{~A}]_{0} \exp \left(-k_{\mathrm{ps} 1} t\right)\right]
$$

The path length for absorption $l$ was about $2 \mathrm{~cm}$. Using the estimated absorption coefficients ${ }^{5} \epsilon$, for $\mathrm{Na}$ and $\mathrm{K}$, we could calculate the metal concentration on an absolute basis, although this is not necessary for a first-order kinetic analysis. $k_{\mathrm{ps} 1}$ and the initial absorbance, $\epsilon l[\mathrm{~A}]_{0}$, were obtained from roughly 2000 $I(\mathrm{t})$ points with a nonlinear least-squares fitting computer program. ${ }^{2}$ At each set of conditions, usually 5 to 8 values of $k_{\mathrm{ps} 1}$ for [NO] from zero to [NO] $]_{\max }$ were acquired. $k_{\mathrm{ps} 2}$ values and their statistical precision $\sigma_{\mathrm{ps} 2}$ were derived from the slopes of weighted linear plots of $k_{\mathrm{ps} 1}$ vs [NO]. ${ }^{17}$

\section{Ab Initio Methodology}

$\mathrm{Ab}$ initio calculations were performed using the GAUSSIAN $92^{18}$ and GAUSSIAN $94^{19}$ packages. The PESs of reactions 1 , 2 , and 3 were characterized at the HF/6-31G(d) levels of theory.
TABLE 1: Summary of Pseudo-Second-Order Rate Constants for $\mathrm{K}+\mathrm{NO}+(\mathrm{Ar}) \rightarrow \mathrm{KON}+(\mathrm{Ar})$ at $734 \mathrm{~K}$

\begin{tabular}{rccccc}
\hline $\begin{array}{c}P, \\
\text { mbar }\end{array}$ & $\begin{array}{c}\mathrm{M}] \approx[\mathrm{Ar}], \\
10^{18} \mathrm{~cm}^{-3}\end{array}$ & $\begin{array}{c}\tau_{\mathrm{res}}, \\
\mathrm{s}\end{array}$ & $\begin{array}{c}{[\mathrm{K}]_{0},} \\
10^{11} \mathrm{~cm}^{-3}\end{array}$ & $\begin{array}{c}{[\mathrm{NO}]_{\mathrm{max}},} \\
10^{15} \mathrm{~cm}^{-3}\end{array}$ & $\begin{array}{c}\left(k_{\mathrm{ps} 2} \pm \sigma_{\mathrm{kps} 2}\right), 10^{-14} \\
\mathrm{~cm}^{3} \mathrm{molecule}^{-1} \mathrm{~s}^{-1}\end{array}$ \\
\hline 26.9 & 0.266 & 0.7 & 2.3 & 10.3 & $2.56 \pm 0.69$ \\
28.3 & 0.277 & 0.4 & 2.4 & 4.75 & $1.25 \pm 0.15$ \\
28.7 & 0.283 & 0.8 & 2.0 & 10.8 & $3.30 \pm 0.19$ \\
53.6 & 0.525 & 0.7 & 1.4 & 8.90 & $2.50 \pm 0.32$ \\
60.9 & 0.602 & 1.6 & 1.8 & 2.59 & $7.63 \pm 0.61$ \\
69.7 & 0.689 & 1.2 & 1.4 & 14.9 & $8.10 \pm 0.33$ \\
70.2 & 0.689 & 0.9 & 2.7 & 11.9 & $3.72 \pm 0.35$ \\
84.9 & 0.832 & 1.1 & 2.1 & 11.3 & $6.41 \pm 0.71$ \\
111 & 1.08 & 1.4 & 2.6 & 6.85 & $8.81 \pm 0.46$ \\
113 & 1.12 & 1.5 & 1.3 & 6.18 & $13.43 \pm 0.27$ \\
121 & 1.20 & 1.3 & 1.0 & 10.2 & $13.47 \pm 1.20$ \\
122 & 1.21 & 0.6 & 1.1 & 10.2 & $10.03 \pm 0.62$ \\
135 & 1.34 & 1.8 & 1.2 & 7.42 & $15.64 \pm 0.31$ \\
149 & 1.48 & 1.0 & 1.1 & 6.71 & $14.41 \pm 0.82$ \\
159 & 1.57 & 1.1 & 1.9 & 3.18 & $12.87 \pm 0.77$ \\
188 & 1.86 & 1.0 & 0.9 & 4.11 & $19.38 \pm 0.60$ \\
195 & 1.93 & 1.3 & 1.1 & 5.66 & $21.43 \pm 0.85$ \\
208 & 2.06 & 1.4 & 0.7 & 6.08 & $16.84 \pm 1.41$ \\
212 & 2.11 & 1.9 & 0.9 & 4.15 & $27.61 \pm 1.44$ \\
214 & 2.12 & 0.9 & 1.1 & 3.26 & $25.70 \pm 0.97$ \\
229 & 2.27 & 1.0 & 0.9 & 5.13 & $23.64 \pm 0.85$ \\
269 & 2.67 & 1.2 & 0.8 & 2.98 & $25.86 \pm 1.16$ \\
315 & 3.12 & 1.4 & 0.8 & 2.44 & $26.56 \pm 1.49$ \\
327 & 3.25 & 1.2 & 1.1 & 2.91 & $33.27 \pm 1.65$ \\
368 & 3.65 & 1.4 & 0.9 & 3.27 & $42.41 \pm 1.66$ \\
408 & 4.04 & 1.4 & 0.9 & 2.39 & $46.63 \pm 1.54$ \\
& & & & &
\end{tabular}

Internal GAUSSIAN basis sets were employed except for $\mathrm{K}$, where its 6-31G(d) and 6-311+ G(2d) basis sets were imported from the web site of the Environmental Molecular Sciences Laboratory. ${ }^{20}$ Both singlet and triplet PESs were investigated. Vibrational frequencies were calculated at each stationary point on the PES and the true minima were confirmed as having all frequencies real while each transition state (TS) has a single imaginary frequency. Moreover, the nature of the transition structures on the PESs was confirmed by following the intrinsic reaction coordinate. The $\mathrm{HF}$ frequencies were scaled by a standard factor of 0.893 before calculation of the zero-point energy (ZPE) and spin contamination was monitored through $\left\langle S^{2}\right\rangle$, which ideally is 0 for singlets and 2 for triplets. The geometries and vibrational frequencies of the most stable adducts for the three reactions were further analyzed at the UQCISD/ $6-311+\mathrm{G}(2 \mathrm{~d})$ level, and the energy at the UQCISD(T)/6-311+ $\mathrm{G}(2 \mathrm{~d})$ level. In these correlated calculations both the frozen core and full electron correlation treatments were employed.

\section{Results And Discussion}

4.1. K + NO. Kinetic Measurements. Twenty-eight values of $k_{\mathrm{ps} 2}$ were measured for reaction 1 , summarized in Table 1. The total gas concentration [Ar] was varied from $2.7 \times 10^{17}$ to $4.0 \times 10^{18}$ molecule $\mathrm{cm}^{-3}$, corresponding to a variation in pressure of $27-410 \mathrm{mbar}$. [K] $]_{0}$ was varied from $0.7 \times 10^{11}$ to $2.7 \times 10^{11}$ molecule $\mathrm{cm}^{-3}$ and [NO] from $3.8 \times 10^{14}$ to $14.9 \times$ $10^{15}$ molecule $\mathrm{cm}^{-3}$. Under these experimental conditions, the pseudo-first-order condition, where $[\mathrm{K}] \ll[\mathrm{NO}] \ll[\mathrm{Ar}]$, was always satisfied. No notable effect on $k_{\mathrm{ps} 2}$ was seen when the photolysis energy was doubled with all the other experimental parameters kept constant. Therefore, interferences from the photolysis and reaction products are negligible. In addition, the absence of a $k_{\mathrm{ps} 2}$ dependence on $\tau_{\text {res }}$, which varies from 0.4 to $1.9 \mathrm{~s}$, indicates that thermal decomposition of NO was insignificant. A plot of the pseudo-second-order rate constant $k_{\mathrm{ps} 2}$ vs $[\mathrm{M}]$ is shown in Figure 1. A least-squares fit of the data yielded an unrealistic negative intercept ( $2.1 \sigma$ from zero) which 


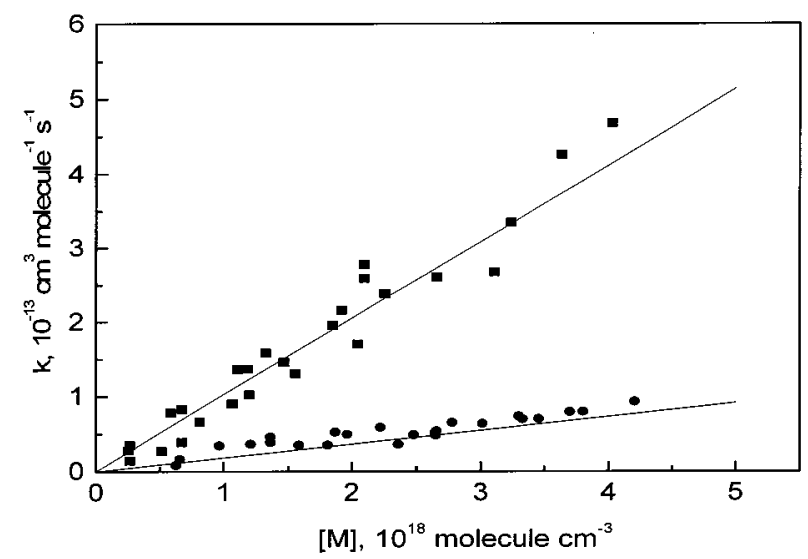

Figure 1. Plot of pseudo-second-order rate constants for $\mathrm{K}+\mathrm{NO}+$ $\mathrm{Ar}$ (squares) and $\mathrm{Na}+\mathrm{NO}+\mathrm{Ar}$ (circles) versus [Ar]. The straight lines correspond to weighted least-squares fits.

could be attributed to the data with smaller statistical errors, i.e., greater weight, obtained at lower versus high pressures. Also, at lower pressures it becomes harder to separate reactive from diffusive loss of $\mathrm{K}$ atoms. To provide a consistent fit without obtaining a negative intercept, we instead constrained the fit to pass through the origin. The fitting yielded a thirdorder rate constant $k_{0}=(1.0 \pm 0.1) \times 10^{-31} \mathrm{~cm}^{6}$ molecule ${ }^{-2}$ $\mathrm{s}^{-1}$ (uncertainties represent $1 \sigma$ ). This value is about $8 \%$ lower than that obtained without forcing the fit through the origin. Allowing $15 \%$ for additional potential systematic errors, the accuracy limit is estimated to be $18 \%$.

The observed third-order kinetics are consistent with formation of an adduct between $\mathrm{K}$ and $\mathrm{NO}$, where in terms of the Lindemann-Hinshelwood mechanism, ${ }^{21,22}$

$$
\begin{gathered}
\mathrm{K}+\mathrm{NO} \rightleftarrows \mathrm{KON}^{*} \\
\mathrm{KON}^{*}+\mathrm{M} \rightarrow \mathrm{KON}+\mathrm{M}
\end{gathered}
$$

the second step, stabilization of the initially excited adduct through collision with a third body $\mathrm{M}$, is rate limiting at low pressures. The abstraction reaction channels are too endothermic to play any role for this reaction, as noted in the Introduction. The following sections describe computational characterization of possible adducts, their binding energies, and RRKM modeling of reactions 5 and 6.

Ab Initio Results. The spin-restricted RHF wave functions for all singlet species were observed to be unstable with respect to relaxation to spin-unrestricted UHF wave functions. The latter

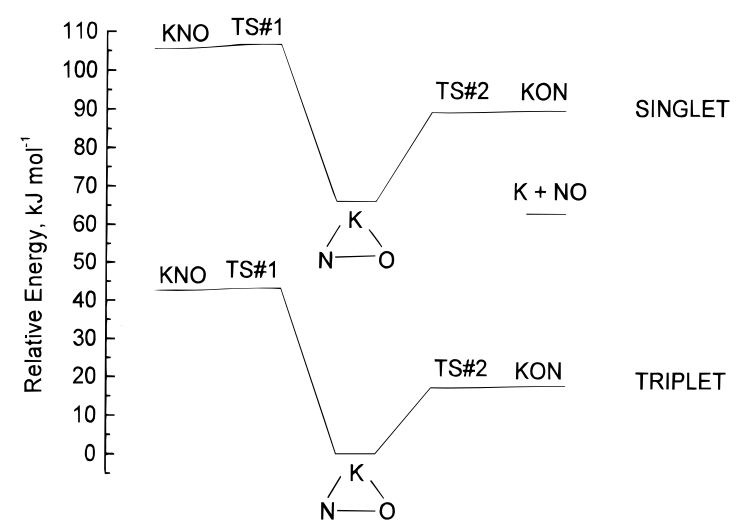

Figure 2. Potential energy surfaces at $\mathrm{UHF} / 6-31 \mathrm{G}(\mathrm{d})$ for $\mathrm{K}+\mathrm{NO}$, energies are relative to the triplet bent adduct (the ZPEs are included).

were therefore employed to characterize stationary points. Despite the high degree of spin contamination $\left(\left\langle S^{2}\right\rangle \approx 1\right.$ rather than 0$)$, this choice is supported by results of calculations on the singlet and triplet states of valence isoelectronic $\mathrm{NO}^{-}$which has a similar RHF $\rightarrow$ UHF instability. The UHF/6-31G(d) singlet-triplet gap is $67 \mathrm{~kJ} \mathrm{~mol}^{-1}$, in good agreement with the experimental value ${ }^{11}$ of $72 \mathrm{~kJ} \mathrm{~mol}^{-1}$, whereas if the RHF/6$31 \mathrm{G}(\mathrm{d})$ energy is employed for the singlet state, then the computed gap is $205 \mathrm{~kJ} \mathrm{~mol}^{-1}$. At the UHF/6-31G(d) level, the geometry, vibrational frequencies, and energies for the minima and transition states on the singlet and triplet surfaces are listed in Table 2. Calculations show the triplet PES has a lower energy than the singlet and that the triplet bent adduct is the most stable. Figure 2 displays the energies at the UHF/6-31G(d) level of various minima and transition states relative to the triplet bent adduct energy. Two TS structures were located between the bent and the linear adducts on both surfaces. On the triplet surface, the energy barrier from the linear KON and KNO to the bent form vanishes or becomes negligible after inclusion of the zeropoint energies. The most stable adduct corresponds to the bent structure where $\mathrm{K}$ lies across the $\mathrm{N}-\mathrm{O}$ bond. The energy difference between the bent adduct and linear KON is about $17.5 \mathrm{~kJ} \mathrm{~mol}^{-1}$. Thus, both structures might be present at the experimental temperature and might easily isomerize. Meanwhile, the formation of the other linear adduct KNO is probable at combustion temperatures. No barrier was found between the reactants and the triplet bent adduct.

The $\mathrm{N}-\mathrm{O}$ bond length $(1.252 \AA)$ and the $\mathrm{N}-\mathrm{O}$ stretching vibrational frequency $\left(1415 \mathrm{~cm}^{-1}\right)$ in the triplet bent adduct at the UQCISD/6-311+ G(2d) level are found to be closer to those

\begin{tabular}{|c|c|c|c|c|c|}
\hline & $\mathrm{K}-\mathrm{N}-\mathrm{O}$ & $\mathrm{K}-\mathrm{O}-\mathrm{N}$ & bent $\mathrm{KON}$ & TS 1 & TS 2 \\
\hline$r_{\mathrm{K}-\mathrm{N}}(\mathrm{S})$ & 2.376 & 3.626 & 2.564 & 2.510 & 3.463 \\
\hline$r_{\mathrm{K}-\mathrm{O}}(\mathrm{S})$ & 3.589 & 2.263 & 2.420 & 3.440 & 2.281 \\
\hline$r_{\mathrm{N}-\mathrm{O}}(\mathrm{S})$ & 1.213 & 1.255 & 1.245 & 1.266 & 1.256 \\
\hline$a_{\mathrm{KNO}}(\mathrm{S})$ & 180.0 & 0.0 & 69.2 & 128.0 & 15.8 \\
\hline$r_{\mathrm{K}-\mathrm{N}}(\mathrm{T})$ & 2.390 & 3.521 & 2.592 & 2.435 & 3.45 \\
\hline$r_{\mathrm{K}-\mathrm{O}}(\mathrm{T})$ & 3.907 & 2.259 & 2.416 & 3.42 & 2.280 \\
\hline$r_{\mathrm{N}-\mathrm{O}}(\mathrm{T})$ & 1.517 & 1.262 & 1.252 & 1.222 & 1.262 \\
\hline$a_{\mathrm{KNO}}(\mathrm{T})$ & 180.0 & 0.0 & 67.8 & 136.8 & 17.4 \\
\hline$E(\mathrm{UHF}, \mathrm{S})^{b}$ & -728.30565 & -728.31111 & -728.32051 & -728.30479 & -728.31102 \\
\hline$E(\mathrm{RHF}, \mathrm{S})^{b}$ & -728.258161 & -728.25507 & -728.28154 & -728.28154 & -728.25505 \\
\hline$E(\mathrm{UHF}, \mathrm{T})^{b}$ & -728.32953 & -728.33850 & -728.34552 & -728.32895 & -728.33838 \\
\hline frequencies $(\mathrm{S})^{c}$ & $71,71,328,1856$ & $47,47,358,1589$ & $270,342,1624$ & $108 i, 329,1799$ & $62 \mathrm{i}, 356,1558$ \\
\hline frequencies $(\mathrm{T})^{c}$ & $57,57,285,1638$ & $47,47,320,1381$ & $212,306,1415$ & $87 \mathrm{i}, 294,1595$ & $55 \mathrm{i}, 320,1380$ \\
\hline$\left\langle S^{2}\right\rangle(\mathrm{S})$ & 1.015 & 1.013 & 0.999 & 1.016 & 1.101 \\
\hline$\left\langle S^{2}\right\rangle(\mathrm{T})$ & 2.028 & 2.023 & 2.029 & 2.050 & 2.023 \\
\hline
\end{tabular}

TABLE 2: Data for UHF/6-31G(d) Stationary Points on the Singlet and Triplet Surfaces of K + NO$^{a}$

${ }^{a}$ Distances in $10^{-10} \mathrm{~m}$ and angles in degrees. ${ }^{b}$ Energies without ZPE, in hartrees. 1 hartree $\approx 2625 \mathrm{~kJ} \mathrm{~mol}^{-1}$. ${ }^{c}$ frequencies scaled by 0.893 , in $\mathrm{cm}^{-1}$. 
TABLE 3. Results for the Optimized Triplet Bent Adducts and NO at UQCISD/6-311+ G(2d $)^{a}$

\begin{tabular}{|c|c|c|c|c|c|c|c|c|}
\hline & $\mathrm{LiON}$ & $\mathrm{NaON}$ & KON & $\mathrm{Li}$ & $\mathrm{Na}$ & K & NO & $\mathrm{NO}^{-}$ \\
\hline$r_{\mathrm{N}-\mathrm{O}}(\mathrm{T})$ & $\begin{array}{l}1.283 \\
(1.281)\end{array}$ & $\begin{array}{l}1.284 \\
(1.280)\end{array}$ & $\begin{array}{l}1.278 \\
(1.276)\end{array}$ & - & - & - & $\begin{array}{l}1.158 \\
(1.156)\end{array}$ & $\begin{array}{l}1.274 \\
(1.272)\end{array}$ \\
\hline$r_{\mathrm{M}-\mathrm{N}}(\mathrm{T})$ & $\begin{array}{l}1.913 \\
(1.899)\end{array}$ & $\begin{array}{l}2.276 \\
(2.247)\end{array}$ & $\begin{array}{l}2.564 \\
(2.560)\end{array}$ & - & - & - & - & - \\
\hline$r_{\mathrm{M}-\mathrm{O}}(\mathrm{T})$ & $\begin{array}{l}1.806 \\
(1.795)\end{array}$ & $\begin{array}{l}2.201 \\
(2.169)\end{array}$ & $\begin{array}{l}2.478 \\
(2.476)\end{array}$ & - & - & - & - & - \\
\hline$a_{\mathrm{MNO}}(\mathrm{T})$ & $\begin{array}{l}65.4 \\
(65.4)\end{array}$ & $\begin{array}{l}70.2 \\
(69.8)\end{array}$ & $\begin{array}{l}71.7 \\
(71.7)\end{array}$ & - & - & - & - & - \\
\hline $\begin{array}{l}\text { UQCISD(T)/ } \\
\quad 6-311+\mathrm{G}(2 \mathrm{~d})^{b}\end{array}$ & -137.15339 & -291.54210 & -729.05382 & -7.43203 & -161.84598 & -599.35285 & -129.67019 & -129.66467 \\
\hline frequencies $^{c}$ & $362,682,1323$ & $264,392,1341$ & $248,305,1345$ & - & - & - & 1766 & 1360 \\
\hline $\begin{array}{l}\mathrm{UQCISD}(\mathrm{T})=\text { full/ } \\
6-311+\mathrm{G}(2 \mathrm{~d})^{b}\end{array}$ & -137.21198 & -291.72197 & -729.20655 & -7.44735 & -161.98435 & -599.46347 & -129.71202 & -129.70730 \\
\hline frequencies $^{d}$ & $370,693,1329$ & $278,394,1337$ & $249,305,1350$ & - & - & - & 1762 & 1367 \\
\hline
\end{tabular}

${ }^{a}$ Distances in $10^{-10} \mathrm{~m}$ and angles in degrees. Results in parentheses obtained with the UQCISD $=$ full theory, where all electrons were included in the correlation treatment. ${ }^{b}$ Energies in hartrees including ZPE. ${ }^{c}$ Unscaled frequencies at UQCISD/6-311+ G(2d), in $\mathrm{cm}^{-1}$. ${ }^{d}$ Unscaled frequencies at UQCISD $=$ full/6-311+ G(2d), in $\mathrm{cm}^{-1}$.

of the ionic than the radical form of NO (see Table 3). Furthermore, the Mulliken charge distributions on $\mathrm{K}, \mathrm{N}$, and $\mathrm{O}$ are $+0.88,-0.38$, and -0.51 , respectively. This clearly shows that $\mathrm{K}$ donates charge to $\mathrm{NO}$ and that the adduct could be viewed as mainly ionic. This helps rationalize the triplet ground state: as in isoelectronic $\mathrm{O}_{2}$, Hund's rule favors a triplet ground state for $\mathrm{NO}^{-}$. The geometries of the triplet bent adduct obtained with the frozen core and full electron correlation at the UQCISD/ $6-311+\mathrm{G}(2 \mathrm{~d}$ ) level are similar (see Table 3). The K-NO bond energies with both methods are quite similar. Thus the frozen core approximation appears to work well for $\mathrm{K}^{+} \mathrm{NO}^{-}$, even though $\mathrm{K}^{+}$has no valence electrons.

$K-O N$ Bond Energy Calculation. The unimolecular kinetics of the reverse of reactions 5 and 6 , that is, the dissociation of the triplet bent adduct KON, were analyzed in terms of RRKM theory using the UNIMOL ${ }^{23}$ program for an argon bath gas.

At low pressures, the rate of product formation is pressure dependent because the energy transfer from the bath gas $\mathrm{M}$ to adduct is rate limiting. The rate for $\mathrm{KON}$ decomposition can be expressed as $k_{0, \text { uni }}[\mathrm{M}][\mathrm{KON}]$ where $k_{0, \text { uni }}$ is the low-pressure second-order rate constant. Canonical variational transition state theory was applied to this barrierless reaction. This type of reaction, where the TS is loose, may be analyzed with the Gorin model. ${ }^{24}$ In this model, the TS is assumed to be product-like with a large separation $r^{\dagger}$ between fragments. Consequently, the structures and the vibrational frequencies of the products are kept unchanged in the TS. The separation $r^{\dagger}$ ( $r_{\mathrm{K}-\mathrm{O}}$ was selected in this case) in the transition state is defined as the distance where the high-pressure rate constant is minimized (with the angular momentum unconserved). In the KON case, the potential energy as a function of the bond length was simply represented by a Morse function. The independent rotational mode of the separated fragments, which correlates with the rocking motion of $\mathrm{NO}$ about the breaking bond in the TS, was considered as an internal rotor in the Gorin model. Since the adduct and the TS are close to symmetric tops, we assumed that the energy of rotation about the unique axis is available to help the TS cross the angular momentum barrier and therefore that this mode is "active". The other degenerate two-dimensional rotations were combined and taken as inactive, i.e., uncoupled from the internal degree of freedom. The rate constant for the recombination reaction $k_{0, \text { rec }}$ was obtained using the equilibrium constant

$$
K_{\mathrm{eq}}=\frac{Q(\mathrm{KON})}{Q(\mathrm{~K}) Q(\mathrm{NO})} \exp \left(\frac{E_{0}}{R T}\right)
$$

TABLE 4: Morse Potential and Lennard-Jones Parameters

\begin{tabular}{cccccc}
\hline $\mathrm{TS}$ & $\mathrm{v}\left(\mathrm{cm}^{-1}\right)$ & $r_{\mathrm{e}}(\AA)$ & $\beta\left(\AA^{-1}\right)$ & $\epsilon / k_{\mathrm{b}}$ & $\sigma(\AA)$ \\
\hline $\mathrm{Li} \cdots \mathrm{ON}$ & 682 & 1.806 & 1.857 & 112 & 3.653 \\
$\mathrm{Na} \cdots \mathrm{ON}$ & 392 & 2.201 & 2.293 & 335 & 4.130 \\
$\mathrm{~K} \cdots \mathrm{ON}$ & 305 & 2.478 & 1.625 & 337 & 4.115
\end{tabular}

TABLE 5: Parameters for RRKM Calculations (See Text)

\begin{tabular}{lcccccc}
\hline \multicolumn{1}{c}{$\mathrm{TS}$} & $r^{\dagger}, \AA$ & $v, \mathrm{~cm}^{-1}$ & $\begin{array}{c}B_{\text {int }}(\text { active }), \\
\mathrm{cm}^{-1}\end{array}$ & $\begin{array}{c}B_{\text {ext }}(\text { active }), \\
\mathrm{cm}^{-1}\end{array}$ & $\begin{array}{c}B_{\text {ext }}(\text { inactive }), \\
\mathrm{cm}^{-1}\end{array}$ \\
\hline $\mathrm{Li} \cdots \mathrm{ON}$ & 4.6 & 1768 & 1.618974 & 0.108 & 0.124 \\
$\mathrm{Na} \cdots \mathrm{ON}$ & 4.0 & 1768 & 1.0567 & 0.2019 & 0.106 \\
$\mathrm{~K} \cdots \mathrm{ON}$ & 5.4 & 1768 & 0.974398 & 0.1038 & 0.049
\end{tabular}

and the relationship $K_{\mathrm{eq}}=k_{0, \text { red }} / k_{0, \text { uni. }} Q$ represents the molecular partion function, and the usual assumptions of separability between vibrational and rotational motion, and of harmonic oscillation, were made in our calculations (see later). $k_{0, \text { rec }}$ for different values of the binding energy in the adduct $E_{0}$ at $0 \mathrm{~K}$ was calculated at $734 \mathrm{~K}$, with the UNIMOL suite, until the calculated rate constant matched the experimental low-pressure rate constant $k_{0}$. $\mathrm{Ab}$ initio geometry and frequency results at the UQCISD/6-311+ G(2d) level, summarized in Table 3, were used and the Lennard-Jones parameters $\sigma$ and $\epsilon / k_{\mathrm{b}}$ for KON were taken as those of chlorine molecules. ${ }^{25}$ The input parameters are shown in Tables 4 and 5 . The $E_{0}$ obtained is $104 \mathrm{~kJ}$ $\mathrm{mol}^{-1}$. The calculations show that the $E_{0}$ value is not very sensitive to $\sigma$ and $\epsilon / k_{\mathrm{b}}$, for example, if $\sigma=4.5 \AA$ and $\epsilon / k_{\mathrm{b}}=$ 420 , we find $E_{0}$ to be underpredicted by $13 \%$. A presumed uncertainty of factor of 2 in the calculated $k_{0}$ leads to a $\pm 24 \mathrm{~kJ}$ $\mathrm{mol}^{-1}$ uncertainty in $E_{0}$.

At $905 \mathrm{~K}$, the observed rate constant $k_{\mathrm{ps} 2}$ was about 15 times slower and dependent on the residence time; we believe that the change in $k_{\mathrm{ps} 1}$ was mainly due to reactions other than $\mathrm{K}+$ NO itself. If we suppose that at the highest concentration of NO used $\left(2 \times 10^{16}\right.$ molecule $\left.\mathrm{cm}^{-3}\right)$ less than half of $[\mathrm{K}]_{0}$ was removed by $\mathrm{NO}$, the equilibrium constant for reaction $1 K_{\text {eq }}$, will be less than $8.3 \times 10^{-17} \mathrm{~cm}^{3}$ molecule $^{-1}$. From eq III, this implies an upper limit for the bond energy of $127 \mathrm{~kJ}$ $\mathrm{mol}^{-1}$, which is consistent with the RRKM-bond value of 104 $\mathrm{kJ} \mathrm{mol}^{-1}$ and the QCISD(T)/6-311+ $\mathrm{G}(2 \mathrm{~d})$ ab initio value of $81 \mathrm{~kJ} \mathrm{~mol}^{-1}$.

4.2. Na + NO. Kinetic Results. Twenty-four measurements of $k_{\mathrm{ps} 2}$ were obtained (Table 6) between 64 and 430 mbar, corresponding to total densities $[\mathrm{M}]=(6.4-42) \times 10^{17}$ molecule $\mathrm{cm}^{-3}$. Flash-lamp energy changes varied the initial concentration of sodium $[\mathrm{Na}]_{0}$ over $(0.6-2.4) \times 10^{11}$ molecule $\mathrm{cm}^{-3}$ and NO concentrations covered the range $(0.9-40.3) \times$ 
TABLE 6: Summary of Pseudo-Second-Order Rate Constants for $\mathrm{Na}+\mathrm{NO}+(\mathrm{Ar}) \rightarrow \mathrm{NaON}+(\mathrm{Ar})$ at $734 \mathrm{~K}$

\begin{tabular}{cccccc}
\hline $\begin{array}{c}P, \\
\mathrm{mbar}\end{array}$ & $\begin{array}{c}{[\mathrm{M}] \approx[\mathrm{Ar}],} \\
10^{18} \mathrm{~cm}^{-3}\end{array}$ & $\begin{array}{c}\tau_{\mathrm{res}}, \\
\mathrm{s}\end{array}$ & $\begin{array}{c}{[\mathrm{Na}]_{0},} \\
10^{11} \mathrm{~cm}^{-3}\end{array}$ & $\begin{array}{c}{[\mathrm{NO}]_{\mathrm{max}},} \\
10^{15} \mathrm{~cm}^{-3}\end{array}$ & $\begin{array}{c}\left(k_{\mathrm{ps} 2} \pm \sigma_{\mathrm{kps} 2}\right), 10^{-14} \\
\mathrm{~cm}^{3} \text { molecule }\end{array} \mathrm{s}^{-1}$ \\
\hline 64.5 & 0.642 & 0.9 & 1.0 & 20.7 & $0.63 \pm 0.07$ \\
67.4 & 0.672 & 1.8 & 1.2 & 40.3 & $1.46 \pm 0.15$ \\
99.4 & 0.981 & 2.6 & 1.3 & 33.7 & $3.23 \pm 0.29$ \\
124 & 1.22 & 2.2 & 1.2 & 17.4 & $3.46 \pm 0.37$ \\
141 & 1.38 & 3.7 & 1.4 & 17.2 & $3.68 \pm 0.41$ \\
141 & 1.38 & 3.7 & 2.4 & 17.2 & $4.39 \pm 0.36$ \\
163 & 1.60 & 2.8 & 1.1 & 13.8 & $3.32 \pm 0.72$ \\
183 & 1.82 & 1.2 & 0.8 & 9.29 & $3.32 \pm 0.48$ \\
192 & 1.88 & 3.4 & 1.3 & 16.3 & $5.03 \pm 0.54$ \\
199 & 1.98 & 2.6 & 1.0 & 8.80 & $4.76 \pm 0.80$ \\
226 & 2.24 & 3.0 & 1.3 & 8.46 & $5.69 \pm 0.55$ \\
240 & 2.37 & 3.2 & 0.6 & 13.7 & $3.44 \pm 0.18$ \\
253 & 2.49 & 3.3 & 1.7 & 10.8 & $4.69 \pm 0.32$ \\
268 & 2.66 & 1.8 & 0.6 & 10.4 & $5.01 \pm 0.34$ \\
269 & 2.67 & 3.6 & 0.8 & 19.5 & $4.64 \pm 0.41$ \\
268 & 2.66 & 1.8 & 1.0 & 8.32 & $5.18 \pm 0.44$ \\
281 & 2.79 & 1.5 & 0.9 & 4.30 & $6.31 \pm 0.86$ \\
308 & 3.03 & 2.0 & 0.9 & 9.10 & $6.18 \pm 0.63$ \\
336 & 3.31 & 4.4 & 1.4 & 14.4 & $7.17 \pm 0.90$ \\
339 & 3.34 & 2.2 & 1.0 & 10.0 & $6.79 \pm 0.86$ \\
354 & 3.47 & 3.1 & 0.8 & 5.14 & $6.82 \pm 1.40$ \\
375 & 3.71 & 3.3 & 0.8 & 3.38 & $7.73 \pm 1.40$ \\
389 & 3.81 & 3.4 & 0.7 & 5.64 & $7.75 \pm 0.65$ \\
426 & 4.22 & 3.8 & 0.8 & 3.11 & $9.12 \pm 0.58$
\end{tabular}

$10^{15}$ molecule $\mathrm{cm}^{-3}$. For this reaction and under the pseudofirst-order conditions, the measured $k_{\mathrm{ps} 2}$ values did not show any significant change with either the flash energy or the residence time $\tau_{\text {res. }}$. This rules out any secondary reaction from the photolysis products or decomposition of NO (via $\tau_{\text {res }}$ ) and consequently shows that the reaction was successfully isolated. At higher temperatures, $849 \mathrm{~K}$, it was found that the observed $k_{\mathrm{ps} 2}$ became very slow and dependent on $\tau_{\text {res }}$; possibly the addition reaction no longer proceeded, and the changes in $k_{\mathrm{ps} 1}$ reflected reaction of $\mathrm{Na}$ with decomposition products of $\mathrm{NO}$. Pseudo-second-order rate constants $k_{\mathrm{ps} 2}$ are plotted against [M] in Figure 1.

Following the same weighted linear fitting procedure as before, the derived third-order rate constant was found to be $k_{0}$ $=(1.9 \pm 0.2) \times 10^{-32} \mathrm{~cm}^{6}$ molecule ${ }^{-2} \mathrm{~s}^{-1}$ (the uncertainty represents $1 \sigma$ ). As in the previous reaction, the unconstrained intercept is $2 \sigma$ from zero and the slope does not vary significantly (about 10\%) with the choice of the fitting procedure. Allowing $15 \%$ for additional potential systematic errors, the $95 \%$ accuracy limit is estimated to be $\pm 25 \%$.

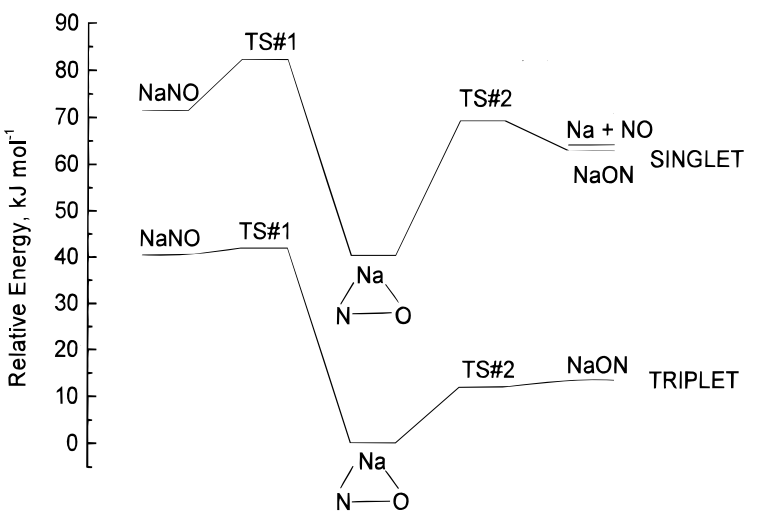

Figure 3. Potential energy surfaces at UHF/6-31G(d) for $\mathrm{Na}+\mathrm{NO}$, energies are relative to the triplet bent adduct (the ZPEs are included).

Ab Initio Results. There is considerable similarity between the PES of this reaction and the previous one, and the triplet bent adduct is again found to be the most stable. At the UHF/ 6-31G(d) level, the geometry, vibrational frequencies, and energies for the minima and transition states on the singlet and triplet surfaces are listed in Table 7 . Figure 3 displays the energies at the UHF/6-31G(d) level of various minima and transition states relative to the triplet bent adduct. Two TS structures were found for each PES and were located between the linear and the bent adducts. The bent adduct is the most stable on both surfaces. The ZPE-corrected energy barrier from the linear structure $\mathrm{NaNO}$ to the bent form is about $1.5 \mathrm{~kJ} \mathrm{~mol}^{-1}$, and the other barrier from the linear $\mathrm{NaON}$ vanishes when the ZPEs are included. The geometries of the triplet bent adduct, optimized at the UQCISD/6-311+ G(2d) level with full electron correlation and with the frozen core approximation, are almost identical (see Table 3) and the UQCISD(T)/6-311+ G(2d) Na$\mathrm{ON}$ bond energies are very close. Again, the $\mathrm{N}-\mathrm{O}$ bond length $(1.255 \AA)$ and the $\mathrm{N}-\mathrm{O}$ stretching vibrational frequency (1432 $\left.\mathrm{cm}^{-1}\right)$ in the triplet bent adduct, at UQCISD/6-311+ G(2d), are found to be close to those of ionic $\mathrm{NO}^{-}$. With Mulliken charge distributions on $\mathrm{Na}, \mathrm{O}$, and $\mathrm{N}$ of $+0.78,-0.48$, and -0.30 , respectively, one would expect again that bent $\mathrm{NaON}$ is largely ionic. According to the isomerization equilibrium constant, calculated with ab initio results at the HF level, linear $\mathrm{NaON}$ may be present along with the bent form, and at combustion temperatures all three isomers might be formed.

$\mathrm{Na}-\mathrm{ON}$ Bond Energy Calculation. The same procedure used to derive the $\mathrm{K}-\mathrm{ON}$ bond strength was repeated here for $\mathrm{Na}-$ ON. The input parameters for the UNIMOL code are sum-

TABLE 7: Data for UHF/6-31G(d) Stationary Points on the Singlet and Triplet Surfaces of Na $+\mathrm{NO}^{a}$

\begin{tabular}{llllll}
\hline & \multicolumn{1}{c}{$\mathrm{Na}-\mathrm{N}-\mathrm{O}$} & $\mathrm{Na}-\mathrm{O}-\mathrm{N}$ & bent NaON & TS 1 & TS 2 \\
\hline$r_{\mathrm{Na}-\mathrm{N}}(\mathrm{S})$ & 2.072 & 3.225 & 2.251 & 2.142 & 3.238 \\
$r_{\mathrm{Na}-\mathrm{O}}(\mathrm{S})$ & 3.275 & 1.969 & 2.130 & 3.039 & 2.011 \\
$r_{\mathrm{N}-\mathrm{O}}(\mathrm{S})$ & 1.203 & 1.256 & 1.247 & 1.214 & 1.261 \\
$a_{\mathrm{NaNO}}(\mathrm{S})$ & 180.0 & 0.0 & 68.2 & 127.6 & 27.7 \\
$r_{\mathrm{Na}-\mathrm{N}}(\mathrm{T})$ & 2.078 & 3.233 & 2.285 & 2.128 & 3.198 \\
$r_{\mathrm{Na}-\mathrm{O}}(\mathrm{T})$ & 3.286 & 1.969 & 2.117 & 3.074 & 2.011 \\
$r_{\mathrm{N}-\mathrm{O}}(\mathrm{T})$ & 1.208 & 1.264 & 1.255 & 1.218 & 1.268 \\
$a_{\mathrm{NaNO}(\mathrm{T})}$ & 180.0 & 0.0 & 66.2 & 131.5 & 27.1 \\
$E(\mathrm{UHF}, \mathrm{S})^{b}$ & -291.07208 & -291.07615 & -291.08452 & -291.06879 & -291.07507 \\
$E(\mathrm{RHF}, \mathrm{S})^{b}$ & -291.02853 & -291.01981 & -291.04837 & -291.02625 & -291.01784 \\
$E(\mathrm{UHF}, \mathrm{T})^{b}$ & -291.09433 & $85,85,420,1407$ & -291.10916 & -291.09224 & -291.10315 \\
frequencies(S) $^{c}$ & $132,132,384,1670$ & $73,73,422,1378$ & $232,374,1432$ & $143 \mathrm{i}, 366,1586$ & $103 \mathrm{i}, 415,1386$ \\
frequencies(T) $^{c}$ & $109,109,375,1662$ & 1.013 & 0.993 & $142 \mathrm{i}, 380,1592$ & $96 \mathrm{i}, 421,1359$ \\
$\left\langle S^{2}\right\rangle(\mathrm{S})$ & 1.015 & 2.023 & 2.036 & 1.019 & 1.015 \\
$\left\langle S^{2}\right\rangle(\mathrm{T})$ & 2.029 & & 2.035 & 2.028
\end{tabular}

${ }^{a}$ Distances in $10^{-10} \mathrm{~m}$ and angles in degrees. ${ }^{b}$ Energies in hartrees without ZPE. ${ }^{c}$ Frequencies scaled by 0.893 , in $\mathrm{cm}^{-1}$. 
TABLE 8: Data for UHF/6-31G(d) Stationary Points on the Singlet and Triplet Surfaces of Li $+\mathrm{NO}^{a}$

\begin{tabular}{|c|c|c|c|c|c|}
\hline & $\mathrm{Li}-\mathrm{N}-\mathrm{O}$ & $\mathrm{Li}-\mathrm{O}-\mathrm{N}$ & bent LiON & TS 1 & TS 2 \\
\hline$r_{\mathrm{Li}-\mathrm{N}}(\mathrm{S})$ & 1.745 & 2.889 & 1.858 & 1.827 & 2.627 \\
\hline$r_{\mathrm{Li}-\mathrm{O}}(\mathrm{S})$ & 2.929 & 1.651 & 1.761 & 2.637 & 1.697 \\
\hline$r_{\mathrm{N}-\mathrm{O}}(\mathrm{S})$ & 1.184 & 1.238 & 1.227 & 1.214 & 1.268 \\
\hline$a_{\mathrm{LiNO}}(\mathrm{S})$ & 180.0 & 0.0 & 66 & 118.9 & 32.3 \\
\hline$r_{\mathrm{Li}-\mathrm{N}}(\mathrm{T})$ & 1.749 & 2.902 & 1.995 & 1.814 & 2.572 \\
\hline$r_{\mathrm{Li}-\mathrm{O}}(\mathrm{T})$ & 2.947 & 1.636 & 1.768 & 2.662 & 1.7 \\
\hline$r_{\mathrm{N}-\mathrm{O}}(\mathrm{T})$ & 1.198 & 1.266 & 1.259 & 1.217 & 1.276 \\
\hline$a_{\mathrm{LiNO}}(\mathrm{T})$ & 180.0 & 0.0 & 60.9 & 121.6 & 35.4 \\
\hline$E(\mathrm{UHF}, \mathrm{S})^{b}$ & -136.68825 & -136.69439 & -136.70122 & -136.68052 & -136.69177 \\
\hline$E(\mathrm{RHF}, \mathrm{S})^{b}$ & -136.64657 & -136.63720 & -136.67380 & -136.63743 & -136.63337 \\
\hline$E(\mathrm{UHF}, \mathrm{T})^{b}$ & -136.70937 & -136.72259 & -136.72382 & -136.70411 & -136.72034 \\
\hline frequencies $(\mathrm{S})^{c}$ & $205,205,666,1728$ & $124,124,734,1402$ & $382,657,1418$ & $207 i, 629,1605$ & $148 \mathrm{i}, 728,1349$ \\
\hline frequencies $(\mathrm{T})^{c}$ & $177,177,657,1720$ & $109,109,735,1377$ & $278,664,1371$ & $177 \mathrm{i}, 647,1604$ & $121 \mathrm{i}, 735,1319$ \\
\hline$\left\langle S^{2}\right\rangle(\mathrm{S})$ & 1.015 & 1.012 & 0.948 & 1.020 & 1.015 \\
\hline$\left\langle S^{2}\right\rangle(\mathrm{T})$ & 2.026 & 2.021 & 2.034 & 2.038 & 2.029 \\
\hline
\end{tabular}

${ }^{a}$ Distances in $10^{-10} \mathrm{~m}$ and angles in degrees. ${ }^{b}$ energies in Hartrees without ZPE. ${ }^{c}$ Frequencies scaled by 0.893 , in $\mathrm{cm}^{-1}$

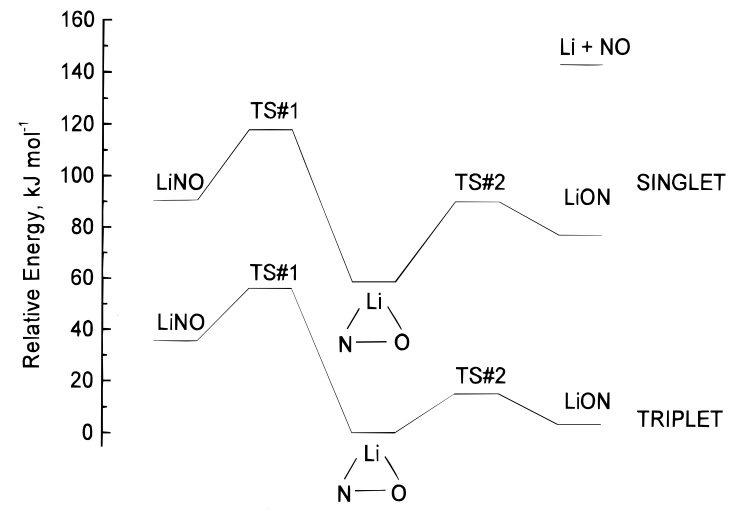

Figure 4. Potential energy surfaces at UHF/6-31G(d) for $\mathrm{Li}+\mathrm{NO}$, energies are relative to the triplet bent adduct (the ZPEs are included).

marized in Table 5; and the Morse potential and Lennard-Jones parameters $^{25} \sigma$ and $\epsilon / k_{\mathrm{b}}$ (taken as those of COS) are listed in Table 5. The RRKM calculations give $E_{0}=66 \mathrm{~kJ} \mathrm{~mol}^{-1}$ with an uncertainty of $\pm 23 \%$ if one assumes an uncertainty of a factor of 2 in $k_{0}$. This bond energy is in very good agreement with the $\mathrm{ab}$ initio one calculated at the UQCISD(T) level of $68 \mathrm{~kJ}$ $\mathrm{mol}^{-1}$. As we mentioned earlier, we found the reaction to proceed very slowly at $849 \mathrm{~K}$. With $[\mathrm{NO}]=6.4 \times 10^{15}$ molecule $\mathrm{cm}^{-3}, k_{\mathrm{ps} 1}$ was barely distinguishable from $k_{\mathrm{diff}}$. If we consider that less than half of the $[\mathrm{Na}]_{0}$ is removed by reaction $2, K_{\mathrm{eq}}$ is found to be $<1.6 \times 10^{-16}$ molecule $\mathrm{cm}^{-3}$ and consequently $E_{0}$ should be below $126 \mathrm{~kJ} \mathrm{~mol}^{-1}$.

4.3. $\mathbf{L i}+$ NO. Ab initio Results. The PES of this reaction is qualitatively identical to the PESs for reactions 1 and 2. The difference is the energy gaps between the different structure and the reactants. Table 8 shows the geometry, vibrational frequencies, and energies, at the UHF/6-31G(d) level, for the TSs and stable adducts on both surfaces. The energies of various minima and transition states relative to the triplet bent adduct energy, at the UHF/6-31G(d) level, are displayed on Figure 4. There is no energy barrier from reactants to the stable structures found on both PESs. While the energy of the linear LiNO, on the triplet surface, is different from the bent form by approximately $35 \mathrm{~kJ} \mathrm{~mol}^{-1}$, the linear LiON energy is above the latter by only $\sim 3 \mathrm{~kJ} \mathrm{~mol}^{-1}$. The isomerization energy barriers from $\mathrm{LiON}$ and LiNO to the bent adduct are about 12 and 20 $\mathrm{kJ} \mathrm{mol}^{-1}$, respectively. The geometry and the frequencies at the UQCISD/6-311+ G(2d) level with the frozen core and the full electron correlation approximations are very close. The $\mathrm{Li}-$ ON bond energy of the triplet bent adduct at the UQCISD(T)/ $6-311+\mathrm{G}(2 \mathrm{~d})$ level with the frozen core approximation showed no significant change when we included full electron correlation (see Table 3).

The LiNO adduct was initially prepared in solution by Asmussen ${ }^{26}$ and its infrared spectrum was identified by Andrews and Pimentel ${ }^{27}$ in a frozen Ar matrix. They measured the frequencies for the bending, $\mathrm{Li}-\mathrm{O}$ stretching, and $\mathrm{N}-\mathrm{O}$ stretching modes as 333,650 , and $1352 \mathrm{~cm}^{-1}$, respectively. These frequencies are in good agreement with our calculations at the UQCISD/6-311+ G(2d) level (see Table 3). With an empirical correlation, Andrews and Pimentel employed their frequencies to derive an approximate geometry. Their estimated values of $\mathrm{r}_{\mathrm{Li}-\mathrm{O}}=1.63 \AA, r_{\mathrm{N}-\mathrm{O}}=1.30 \AA$, and $a_{\mathrm{LiON}}=100^{\circ}$ are somewhat different from our ab initio results.

At $734 \mathrm{~K}$, only the bent and the linear LiON could be formed but at temperatures above $2000 \mathrm{~K}$, linear LiNO might be present in a small proportion. The calculations showed that the charge distribution around $\mathrm{Li}, \mathrm{N}$, and $\mathrm{O}$ is $+0.61,-0.22$, and -0.38 , respectively. This charge distribution, together with the closeness of $r_{\mathrm{N}-\mathrm{O}}$ and the $\mathrm{N}-\mathrm{O}$ stretching vibrational frequency to those of the $\mathrm{NO}^{-}$, favors the assumption that LiNO is significantly ionic.

Kinetics. $k_{0, \text { rec }}$ for reaction 3 , with the theoretical value of $E_{0}$ $=134 \mathrm{~kJ} \mathrm{~mol}^{-1}$, was calculated at $734 \mathrm{~K}$. Ab initio results at the UQCISD/6-311+ G(2d) level, summarized in Table 3, were used and the Lennard-Jones parameters $\sigma$ and $\epsilon / k_{\mathrm{b}}$ for LiNO were assumed to be similar to those of fluorine molecules. ${ }^{25}$ The input parameters are shown in Tables 4 and 5. The RRKM calculations yield a predicted $k_{0, \text { rec }}$ of $1.42 \times 10^{-31} \mathrm{~cm}^{6}$ molecule ${ }^{-2} \mathrm{~s}^{-1}$.

PES for Li Orbiting around NO. If the ab initio results are accurate, at combustion temperatures one can expect that an equilibrium might be established between the three different adducts, and that in effect the Li atom may orbit the NO group. This hypothesis was first mentioned by Clementi et al. ${ }^{28}$ for LiCN, which they called a polytopic bond. To investigate more closely the triplet surface for reaction 3 , more points were calculated at the HF/6-31G(d) level of theory, describing the motion of $\mathrm{Li}$ around NO. In these calculations, we kept the bond length $\mathrm{r}_{\mathrm{N}-\mathrm{O}}$ constant at the average $\mathrm{HF} / 6-31 \mathrm{G}(\mathrm{d})$ value of $1.24 \AA$. The origin of the axis system was placed at the center of $\mathrm{N}-\mathrm{O}$ bond. The distance $r$ from $\mathrm{Li}$ to the origin and the angle a between $\mathrm{Li}$, origin, and $\mathrm{O}$ were varied over $0-3.5 \AA$ and $0-180^{\circ}$, respectively. Over 3000 points were generated along the PES and converted to Cartesian coordinates. The computed energies are shown in Figure 5 as a contour plot. We have presented 140 contours between the highest and the 


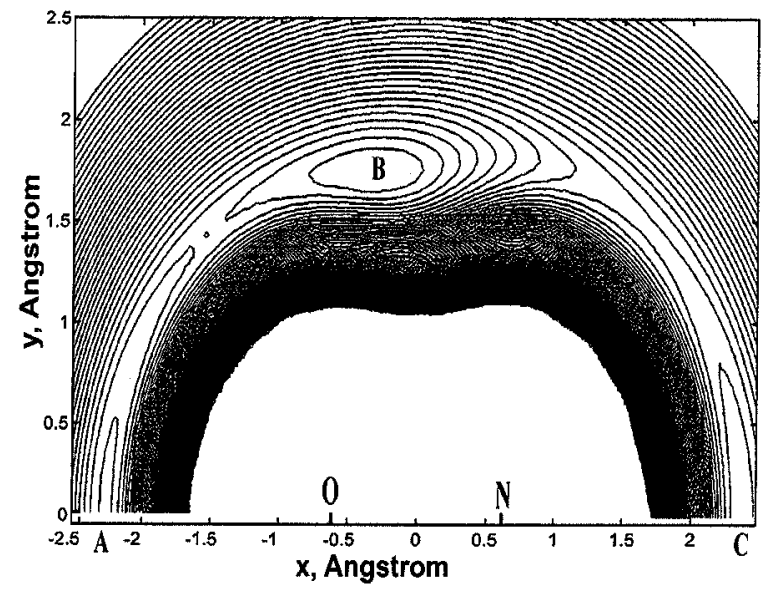

Figure 5. Energy surface of the lithium atom orbiting around NO. The origin of this axis system is in the midbond length of $\mathrm{NO}(x, y)=$ $(0,0)$ and the atoms $\mathrm{N}$ and $\mathrm{O}$ are on the $x$-axis. The interval between each contour is about $1.1 \mathrm{~kJ}$. The positions $\mathrm{A}, \mathrm{B}$, and $\mathrm{C}$ represent linear LiON, bent LiON, and linear LiNO, respectively.

lowest energy of -136.71033 and -136.65169 hartree, respectively. The inner contours correspond to repulsion as Li closely approches $\mathrm{N}$ and $\mathrm{O}$, and we notice that the contours with the lowest energies occupy more space around $\mathrm{O}$ than $\mathrm{N}$, indicating that bonding to the $\mathrm{O}$ atom is favored. The polytopic interaction between alkali metals and NO will likely lead to anharmonicity in the vibrational spectrum, and possible coupling with overall molecular rotation. This represents an additional source of uncertainity in the RRKM calculations performed here, although full derivation of the molecular energy levels is a complex issue. ${ }^{29,30}$

4.4. General Comments. There is no simple trend in the A-ON bond strengths of the bent adducts, with Li bound the tightest to $\mathrm{NO}$, then $\mathrm{K}$, then $\mathrm{Na}$. Although the reactivity of alkali metals toward NO will depend on several factors, we notice that it increases with the bond strength, which leads to increased densities of states at the transition state. Analogous recombination reaction rates of alkali metals with $\mathrm{O}_{2}$ are at least 12 times faster than those with $\mathrm{NO}$, which perhaps partly reflects the greater bond strength in the superoxide adducts. ${ }^{6}$ On the basis of the harpoon mecanism, ${ }^{31}$ we have calculated the crossing distances between the covalent $\mathrm{A}-\mathrm{NO}$ and the ionic $\mathrm{A}^{+}-\mathrm{NO}^{-}$ surfaces using the $\mathrm{G} 2$ electronic affinity of $\mathrm{NO}^{14}$ and the ionization potential of $\mathrm{A}$ from Lias et al. ${ }^{12}$ The calculated values for reactions 1,2, and 3 are 2.6, 2.8, and $3.3 \AA$, respectively. These distances are much shorter than the bond length found in the loose transition states (see Table 5) and therefore longrange electron transfer should not be a controlling factor in the process of the adduct formation.

\section{Conclusions}

The recombination kinetics for $\mathrm{K}+\mathrm{NO}+\mathrm{Ar}$ and $\mathrm{Na}+\mathrm{NO}$ + Ar have been investigated experimentally, and the nature of the adducts characterized by ab initio methods. Largely ionic, triplet state products are the most stable. RRKM modeling based on the theoretical geometries and frequencies yields bond strengths in the adducts similar to those obtained via ab initio calculations. The kinetics and thermochemistry of $\mathrm{Li}+\mathrm{NO}+$ Ar have been predicted.
Acknowledgment. We thank the Robert A. Welch Foundation (Grant B-1174) and the UNT Faculty Research Fund for financial support, and the Air Force Research Laboratory, Wright-Patterson AFB, OH, for computer time.

\section{References and Notes}

78,1175

(1) Husain, D.; Plane, J. M. C. J. Chem. Soc., Faraday Trans. 21982

(2) Husain, D.; Marshall, P.; Plane, J. M. C. J. Chem. Soc., Faraday Trans. 2 1985, 81, 301 2998.

(4) Shi, Y.; Marshall, P. J. Phys. Chem. 1991, 95, 1654

(5) Goumri, A.; Laakso, D.; Rocha, J.-D. R.; Francis, E.; Marshall, P. J. Phys. Chem. 1993, 97, 5295 .

(6) Plane, J. M. C. Gas-Phase Metal Reactions; Fontijn, A., Ed.; NorthHolland: New York, 1992; Chapter 3 and references therein.

(7) Plane, J. M. C. Int. Rev. Phys. Chem. 1991, 10, 55.

(8) Schofield, K. Gas-Phase Metal Reactions; Fontijn, A., Ed.; NorthHolland: New York, 1992, Chapter 23 and references therein.

(9) Perry, R. A.; Miller, J. A. Int. J. Chem. Kinet. 1996, 28, 217

(10) Zamansky, V. M.; Lissianski, V. V.; Maly, P. M.; Ho, L.; Rusli, D.; Gardiner, W. C., Jr. Combust. Flame 1999, 117, 821.

(11) Huber, K. P.; Herzberg, G. Molecular Spectra and Molecular Structure; Van Nostrand Reinhold: New York, 1979; Vol. 4.

(12) Lias, S. G.; Bartmess, J. E.; Liebman, J. F.; Holmes, J. L.; Levin, R. D.; Mallard, G. W. J. Phys. Chem. Ref. Data 1988, 17.

(13) Gaussian-2 (see ref 14) computational studies show that triplet LiN and $\mathrm{NaN}$ are more stable than the singlet states, and have $0 \mathrm{~K}$ bond dissociation energies (BDEs) of about 1.4 and $0.7 \mathrm{eV}$, respectively ( $1 \mathrm{eV}$ $\approx 96.5 \mathrm{~kJ} \mathrm{~mol}^{-1}$ ).

(14) Curtiss, L. A.; Raghavachari, K.; Truck, G. W.; Pople, J. A. J. Chem. Phys. 1991, 94, 7221.

(15) From refs 11 and 12, the BDEs of $\mathrm{LiO}, \mathrm{NaO}$, and $\mathrm{KO}$ are 3.5, 2.6, and $2.8 \mathrm{eV}$, respectively. The BDE of NO is $6.5 \mathrm{eV}$.

(16) Cotton, F. A.; Wilkinson, G. Advanced Inorganic Chemistry, 4th ed.; Wiley-Interscience: New York, 1980; p 423.

(17) Irvin, J. A.; Quickenden, T. I. J. Chem. Educ. 1983, 60, 711

(18) Frisch, M. J.; Truck, G. W.; Head-Gordon, M.; Gill, P. M. W.; Wong, M. W.; Foresman, J. B.; Johnson, B. G.; Schlegel, H. B.; Robb, M. A.; Replogle, E. S.; Gomperts, R.; Andres, J. L.; Raghavachari, K.; Binkley, J. S.; Gonzalez, C.; Martin, R. L.; Fox, D. J.; Defrees, D. J.; Baker, J.; Stewart, J. J. P.; Pople, J. A. Gaussian 92; Gaussian, Inc.: Pittsburgh, PA, 1992.

(19) Frisch, M. J.; Truck, G. W.; Schlegel, H. B.; Gill, P. M. W.; Johnson, B. G.; Robb, M. A.; Cheeseman, J. R.; Keith, T.; Petersson, G. A.; Montgomery, J. A.; Raghavachari, K.; Al-Laham, M. A.; Zakrzewski, V. G.; Ortiz, J. V.; Foresman, J. B.; Cioslowski, J.; Stefanov, B. B.; Nanayakkara, A.; Challacombe, M.; Peng, C. Y.; Ayala, P. Y.; Chen, W.; Wong, M. W.; Andres, J. L.; Replogle, E. S.; Gompert, R.; Martin, R. L.; Fox, D. J.; Binkley, J. S.; Defrees, D. J.; Baker, J.; Stewart, J. J. P.; HeadGordon, M.; Gonzalez, C.; Pople, J. A. Gaussian 94, Revision D.2; Gaussian, Inc.: Pittsburgh, PA, 1995.

(20) Basis sets were obtained from the Extensible Computational Chemistry Environmental Basis set Database, Version 1.0, developed and distributed by Molecular Science Computing Facility, Environmental and Molecular Sciences Laboratory which is part of the Pacific Northwest Laboratory. http://www.emls.pnl.gov:2080/docs/ecce/index.html, 1999.

(21) Gilbert, R. G.; Smith, S. C. Theory of Unimolecular and Recombination Reactions; Blackwell: Oxford, U.K., 1990.

(22) Holbrook, K. A.; Pilling, M. J.; Robertson, S. H. Unimolecular Reactions, 2nd ed.; John Wiley: New York, 1996.

(23) Gilbert, R. G.; Jordan, M. J. T.; Smith, S. C. UNIMOL; Sydney University: Sydney, Australia, 1990

(24) Gorin, E. Acta Physiochim. URSS 1989, 9, 691

(25) Reid, R. C.; Sherwood, T. K. The Properties of Gases and Liquids. Their Estimation and Correlation; McGraw-Hill: New York, 1958.

(26) Asmussen, R. W. Acta Chem. Scand. 1957, 11, 1435.

(27) Andrews, W. L. S.; Pimentel, G. C. J. Chem. Phys. 1966, 44, 2361

(28) Clementi, E.; Kistenmacher, H.; Popkie, H. J. Chem. Phys. 1973, $58,2460$.

(29) Makarewics, J.; Ha, T.-K. J. Mol. Struct.(THEOCHEM) 1994, 315 , 149.

(30) Borondo, F.; Zembekov, A. A.; Benito, R. M. J. Chem. Phys. 1996, 105,5068

(31) Magee, J. J. Chem. Phys. 1940, 8, 687. 